\title{
PRODUÇÃO BIBLIOGRÁFICA DE MARIA DA GLÓRIA BORDINI $^{1}$
}

\section{Livros publicados/organizados}

BORDINI, Maria da Glória. Poética da cidade em Erico Verissimo. 1. ed. Rio de Janeiro, RJ: Ediçôes Makunaima, 2012. v. 1. 335p.

AYALA, Walmir; BORDINI, Maria da Glória (Org.). Melhores contos de Walmir Ayala. São Paulo: Global, 2011. v. 1. 176p.

REMÉDIOS, Maria Luíza Ritzel; BORDINI, Maria da Glória; ZILBERMAN, Regina. Identidades fraturadas: ensaios sobre literatura portuguesa. São Paulo: EDUSP, 2011. v. 1. 176p.

SMOLKA, Ana Lúcia B.; SANTOS, Ezequiel Theodoro; BORDINI, Maria da Glória; ZILBERMAN, Regina. Leitura e desenvolvimento da linguagem. 2. ed. São Paulo, SP: Global; ALB, 2010. 104p.

BORDINI, Maria da Glória (Org.). As cidades imaginadas de Erico Verissimo. 1. ed. Porto Alegre, RS: Gráfica Comunicação Impressa, 2007. v. U. 56 il.p.

BORDINI, Maria da Glória (Org.). Mario Quintana: o anjo da escada. 1. ed. Porto Alegre, RS: Telos Empreendimentos Culturais, 2006. v. U. 116 il.p.

BORDINI, Maria da Glória; REMÉDIOS, Maria Luíza Ritzel; ZILBERMAN, Regina (Org.). Crítica do tempo presente: estudo, difusão e ensino de literaturas de língua portuguesa. 1. ed. Porto Alegre, RS: Nova Prova; AIL; IEL, 2005. v. U. 244p.

BORDINI, Maria da Glória (Org.). Caderno de pauta simples: Erico Verissimo e a crítica literária. 1. ed. Porto Alegre, RS: Instituto Estadual do Livro, 2005. v. U. 364p.

BORDINI, Maria da Glória; SCHÜLER, Fernando Luís (Org.). Cultura e identidade regional. Porto Alegre: EDIPUCRS, 2004. v. 1. 1-114p.

\footnotetext{
${ }^{1}$ Referências extraídas da Plataforma Lattes/CNPq. O levantamento privilegiou livros, capítulos e periódicos, considerando a relevância acadêmica de tais veículos.
} 
BORDINI, Maria da Glória; ZILBERMAN, Regina. O tempo e o vento: história, invenção e metamorfose. Porto Alegre, RS: EDIPUCRS, 2004. v. 1. 208p.

BORDINI, Maria da Glória; ZILBERMAN, Regina; MOREIRA, Maria Eunice; REMÉDIOS, Maria Luíza Ritzel. $\mathbf{O}$ arco e as pedras: fontes primárias, teoria e história da literatura. Belo Horizonte: Editora UFMG, 2004. v. 1.352p.

BORDINI, Maria da Glória (Org.). Lukács e a literatura. Porto Alegre: EDIPUCRS, 2003. 214p.

BORDINI, Maria da Glória (Org.). 35 Melhores Contos do Rio Grande do Sul. 1. ed. Porto Alegre: Instituto Estadual do Livro: CORAG, 2003. v. 1. 324p.

BORDINI, Maria da Glória (Org.). Centro Cultural CEEE Erico Verissimo/CEEE Erico Verissimo Cultural Center. Porto Alegre: Centro Cultural CEEE Erico Verissimo, 2002. 1-152p.

VERISSIMO, Erico; BORDINI, Maria da Glória (Org.). A liberdade de escrever. 2. ed. São Paulo: Globo, 1999. 210p.

PIÑON, Nélida; BORDINI, Maria da Glória (Org.). O cortejo do Divino e outros contos escolhidos. Porto Alegre: L\&PM, 1999. 176p.

BORDINI, Maria da Glória. Criaçáo Literária em Erico Verissimo. 1. ed. Porto Alegre: L\&PM, 1995. v. U. 302p.

ZILBERMAN, Regina; BORDINI, Maria da Glória (Org.). Confissóes do Amor e da Arte. Porto Alegre: Mercado Aberto, 1994. 424p.

BORDINI, Maria da Glória; AGUIAR, Vera Teixeira de. Literatura: A Formação do Leitor. 2. ed. Porto Alegre: Mercado Aberto, 1993. 176p.

BORDINI, Maria da Glória; VERISSIMO, Luis Fernando (Org.). O gigolô das palavras. Porto Alegre, RS: L\&PM, 1993. 112p.

BORDINI, Maria da Glória (Org.). Erico Verissimo: escritor e obra. Porto Alegre, RS: Shopping Center Iguatemi Porto Alegre, 1993. 10p.

BORDINI, Maria da Glória . Fenomenologia e teoria literária. São Paulo: Ed. da Universidade de São Paulo, 1990. 228p. 
BORDINI, Maria da Glória et al. Guia de Leitura Para Alunos de 1o. e 2o. Graus. Sáo Paulo: Cortez/INEP/MEC/CPL/PUCRS, 1989. 292p.

BORDINI, Maria da Glória (Org.). Ilha Difícil: Antologia Poética de Lila Ripoll. Porto Alegre: Ed. da Universidade/UFRGS, 1987. 136p.

BORDINI, Maria da Glória. Poesia Infantil. São Paulo: Ática, 1986. 72p.

BORDINI, Maria da Glória (Org.). Primavera Cruza O Rio: Antologia poética de Mario Quintana. Porto Alegre: Globo, 1985. 96p.

BORDINI, Maria da Glória et al. O Signo Teatral: A Semiologia Aplicada à Arte Dramática. Porto Alegre: Globo, 1977. 84p.

BORDINI, Maria da Glória et al. Masculino, Feminino, Neutro: Ensaios de Semiótica Narrativa. Porto Alegre: Globo, 1976. 138p.

\section{Capítulos de livros publicados}

BORDINI, Maria da Glória. O gênio mau da vida: a Primeira Grande Guerra e a poesia de Manuel Bandeira. In: FLORES, Hilda Agnes Hübner; NUEBERGER, Lotário (Org.). Primeira Guerra Mundial: Reflexos no Brasil. 1. ed. Porto Alegre: Ediplat, 2014, v. 1, p. 181-186.

BORDINI, Maria da Glória. Editando vestígios de um romance inacabado: A hora do sétimo anjo, de Erico Verissimo. In: VASCONCELOS, Eliane; SANTOS, Marcelo (Org.). Arquivo, manuscrito e pesquisa. 1. ed. Rio de Janeiro: Fundação Casa de Rui Barbosa, 2014, v. 1, p. 97-108.

BORDINI, Maria da Glória. Aproximações à lírica. In: BARBOSA, Márcia Helena S.; BECKER, Paulo (Org.). A poesia que se escreve, a poesia que se lê. 1. ed. Passo Fundo, RS: UPF Editora, 2013, p. 11-27.

BORDINI, Maria da Glória. Erico Verissimo e a Cidade Política: O Senhor Embaixador. In: SILVA, Denise Almeida (Org.). Poéticas do espaço, geografias simbólicas. 1. ed. Frederico Westphalen: URI/Frederico Westphalen, 2013, v. U, p. 237-258.

BORDINI, Maria da Glória. História e poesia no Romanceiro da Inconfidência. In: SEFFRIN, André (Org.). Romanceiro da Inconfidência. 12. ed. São Paulo: Global, 2013, v. 1, p. 289-310. 
BORDINI, Maria da Glória. Por uma fenomenologia do conhecimento literário. In: OLIVEIRA, Rejane Pivetta de (Org.). Literatura para pensar e intervir no mundo. 1. ed. Porto Alegre, RS: Ed. UniRitter, 2013, v. U, p. $15-28$.

BORDINI, Maria da Glória. A metáfora pós-moderna na poesia portuguesa contemporânea. In: PETROV, Petar et al. (Org.). Avanços em literatura e cultura portuguesas: Século XX. Santiago de Compostela-Faro: Associação Internacional de Lusitanistas; Através Editora, 2012, v. 3, p. 11-27.

BORDINI, Maria da Glória. El lector de la novela: del texto impreso a la pantalla. In: RETTENMAIER, Miguel; RÖSING, Tania M. K. (Org.). Lectura y formación del lector: estudios en red. Passo Fundo, RS: Ed. Universidade de Passo Fundo, 2012, p. 157-169.

BORDINI, Maria da Glória. Casa de espaço, o poema. In: REMÉDIOS, Maria Luíza Ritzel (Org.). Transversais da memória: história e identidade na literatura portuguesa. 1. ed. Santa Maria, RS: Editora da UFSM, 2012, p. 229-235.

BORDINI, Maria da Glória. Teorias da cidade: do moderno ao pósmoderno. In: GOMES, Gínia Maria (Org.). Narrativas contemporâneas: recortes críticos sobre literatura brasileira. 1. ed. Porto Alegre, RS: Libretos Universidade, 2012, p. 17-28.

BORDINI, Maria da Glória. A representação da história na poesia: o caso Murilo Mendes. In: NUÑEZ, Carlinda Fragale Araújo et al. (Org.). História da literatura: práticas analíticas. 1. ed. Rio de Janeiro, RJ: Ediçōes Makunaima, 2012, v. 1, p. 226-244.

BORDINI, Maria da Glória. Literatura Infanto-Juvenil: Questões Teóricas. In: RÖSING, Tânia Mariza Kuchenbecker; RETTENMAIER, Miguel. (Org.). $\mathbf{3 0}$ anos de Jornadas Literárias: Estudos: edição comemorativa. Passo Fundo: Ed. da Universidade de Passo Fundo, 2011, p. 65-73.

BORDINI, Maria da Glória. Apresentação. In: (Org.). Melhores

Contos de Walmir Ayala. São Paulo, SP: Global, 2011, p. 7-15.

BORDINI, Maria da Glória. O Brasil na memória: Erico Verissimo, viajante. In: JOBIM, José Luís; PELOSO, Silvano. (Org.). Descobrindo o Brasil: sentidos da literatura e da cultura no Brasil. Rio de Janeiro, RJ: EdUERJ, 2011, p. 353-375. 
BORDINI, Maria da Glória. Pensando a poesia infantil de agora. In: ZILBERMAN, Regina; RÖSING, Tania M. K. (Org.). Escola e leitura: velha crise, novas alternativas. São Paulo: Global, 2009, p. 139-161.

BORDINI, Maria da Glória. Erico Verissimo e o realismo machadiano. In: MITIDIERI, André Luís; SILVA, Denise Almeida (Org.). Machado de Assis: Outros Olhares. Frederico Westphalen, RS: URI, 2009, p. 143-155.

BORDINI, Maria da Glória. A virada machadiana nas Ocidentais. In: FANTINI, Marli (Org.). Crônicas da antiga Corte: Literatura e memória em Machado de Assis. Belo Horizonte, MG: Editora UFMG, 2008, p. 123139.

BORDINI, Maria da Glória. "Dão-lalalão" - assim é se lhe parece. In: ZILBERMAN, Regina (Org.). Corpo de baile: romance, viagem e erotismo no sertão. Porto Alegre, RS: EDIPUCRS, 2007, p. 101-108.

BORDINI, Maria da Glória. Quintana e suas cartas: poesia e vida. In: WAHERENDORFF, Ricardo; ZILBERMAN, Regina (Org.). Centenário de Mario Quintana (1906-2006): antologia-poesia e crônica. Brasília, D.F.: Abaré; Fundação Astrogildo Pereira, 2007, p. 286-295.

BORDINI, Maria da Glória. A psicanálise como leitura: literatura um sonho dirigido. In: SOCIEDADE PSICANALÍTICA DE PORTO ALEGRE (Org.). Psicanálise e cultura: homenagem aos 150 anos de Sigmund Freud. São Paulo, SP: Casa do Psicólogo, 2007, p. 255-268.

BORDINI, Maria da Glória. Erico Verissimo e suas cidades imaginadas. In: ; PELLIN, Vera; ROCHA, Malu (Org.). As cidades imaginadas de

Erico Verissimo. Porto Alegre, RS: Gráfica Comunicação Impressa, 2007, p. 2-4.

BORDINI, Maria da Glória. A dimensão engajada da lírica de Oscar Bertholdo. In: CHAVES, Flávio Loureiro; RIBEIRO, Cleodes Maria Piazza (Org.). Matrícula: 40 anos. Caxias do Sul: EDUCS, 2007, p. 67-78.

BORDINI, Maria da Glória. Crises pós-modernas e o fim das utopias: o lugar da literatura. In: HELENA, Lucia (Org.). Literatura, intelectuais e a crise da cultura. Rio de Janeiro: Contra Capa; CNPq, 2007, v. , p. 51-63.

BORDINI, Maria da Glória. Na selva dos livros. In: RÖSING, Tânia M.K.; ROSA, Luciana Lhullier; VARGAS, Maria Lucia Bandeira (Org.). Questóes de vivências de leitura. Passo Fundo: Ed. da Universidade de Passo Fundo, 
2007, p. 23-32.

BORDINI, Maria da Glória. A arte do poeta Quintana. In: ARENDT, João Cláudio; PAVANI, Cinara Ferreira (Org.). Na esquina do tempo: 100 anos com Mario Quintana. Caxias do Sul, RS: EDUCS, 2006, p. 9-16.

BORDINI, Maria da Glória. As meninas: três modelos equívocos de jovens dos anos 70. In: REIS, Carlos (Org.). Figuras da ficçáo. Coimbra: Centro de Literatura Portuguesa/Faculdade de Letras, 2006, p. 71-78.

BORDINI, Maria da Glória. Viciados em Luis Fernando Verissimo. In: MORGANTI, Vera Regina (Org.). Luis Fernando Verissimo: humor \& outras histórias. Porto Alegre, RS: Instituto Estadual do Livro, 2006, p. $31-43$.

BORDINI, Maria da Glória. Poesia em processo. In: . (Org.). Mario

Quintana: o anjo da escada. 1. ed. Porto Alegre, RS: Telos Empreendimentos Culturais, 2006, v. U, p. 23-28.

BORDINI, Maria da Glória. Por trás do Incidente. In: VERISSIMO, Erico. (Org.). Incidente em Antares. 3. ed. São Paulo: Companhia das Letras, 2005, p. 13-18.

BORDINI, Maria da Glória. Acervos literários e universo digital: conexôes abertas. In: ANTUNES, Benedito (Org.). Memória, literatura e tecnologia. São Paulo: Cultura Acadêmica, 2005, p. 37-50.

BORDINI, Maria da Glória. Num caderno de pauta simples. In:

(Org.). Caderno de Pauta Simples: Erico Verissimo e a Crítica Literária. 1. ed. Porto Alegre: Instituto Estadual do Livro, 2005, v. U, p. 9-14.

BORDINI, Maria da Glória. Uma proposta multiculturalista de Estudos Literários. In: ; REMÉDIOS, Maria Luíza Ritzel; ZILBERMAN, Regina (Org.). Crítica do tempo presente: estudo, difusão e ensino de literaturas de língua portuguesa. 1. ed. Porto Alegre, RS: Nova Prova; AIL; IEL, 2005, v. U, p. 222-231.

BORDINI, Maria da Glória. O Rio Grande de Erico Verissimo. In: STRELIAEV, Leonid; TREVISAN, Armindo (Org.). O Rio Grande de Erico Verissimo. Porto Alegre, RS: Leonid Streliaev, Editor, 2004, p. 128129.

BORDINI, Maria da Glória. Erico Verissimo: O Homem e a Obra. In: 
CORONEL, Luiz (Org.). Erico Verissimo - 100 anos - O Tempo e o Vento a Passar. Porto Alegre, RS: Mecenas Editora, 2004, p. 13-22.

BORDINI, Maria da Glória. Acervos sulinos: A fonte documental e o conhecimento literário. In: SOUZA, Eneida Maria de; MIRANDA, Wander Mello (Org.). Arquivos literários. São Paulo: Ateliê Editorial, 2003, v. U, p. 129-139.

BORDINI, Maria da Glória. Psicanálise e literatura. In: GUS, Mauro; DAL ZOT, Jussara Schestatsky; GUS, Ida Ioschpe (Org.). Freud: Releituras Brasileiras. Porto Alegre: Casa do Psicólogo, 2003, p. 111-126.

BORDINI, Maria da Glória. Forma e materialidade histórica. In: (Org.). Lukács e a literatura. Porto Alegre: EDIPUCRS, 2003, p. 33-60.

BORDINI, Maria da Glória. A poesia e seus usos na infância. In: BECKER, Paulo; BARBOSA, Márcia Helena S. (Org.). Questóes de literatura. Passo Fundo, RS: UPF Editora, 2003, p. 67-83.

BORDINI, Maria da Glória. Poesia infantil e produção cultural. In: JACOBY, Sissa (Org.). A criança e a produçáo cultural: do brinquedo à literatura. Porto Alegre, RS: Mercado Aberto, 2003, p. 253-272.

BORDINI, Maria da Glória. Eça de Queirós e Erico Verissimo: a citação como intertexto. In: ZILBERMAN, Regina (Org.). Eças e outros: diálogos com a ficção de Eça de Queirós. Porto Alegre: EDIPUCRS, 2002, p. 73-82.

BORDINI, Maria da Glória. Realismo e resistência em Os Maias e O tempo e o vento. In: ZILBERMAN, Regina (Org.). Eças e outros: diálogos com a ficção de Eça de Queirós. Porto Alegre: EDIPUCRS, 2002, p. 83-90.

BORDINI, Maria da Glória; ZILBERMAN, Regina. Os acervos de escritores e a memória da literatura/Writer's archives and the memory of literature. In: (Org.). Centro Cultural CEEE Erico Verissimo/ CEEE Erico Verissimo Cultural Center. Porto Alegre, RS: Centro Cultural CEEE Erico Verissimo, 2002, p. 53-71.

BORDINI, Maria da Glória. Por trás do Incidente. In: (Org.). In: VERISSIMO, Erico. Incidente em Antares. 2. ed. São Paulo, SP: Editora Globo, 2002, p. 7-13.

BORDINI, Maria da Glória. O Tempo e o Vento: um romance de formação? Pós-colonialismo e identidade política. In: GONÇALVES, Robson Pereira 
(Org.). O Tempo e o Vento: 50 anos. 1. ed. Santa Maria/Bauru: UFSM/ EDUSC, 2000, v. U, p. 45-67.

BORDINI, Maria da Glória. Mulheres e vida literária. In: GOLIN, Cida (Org.). Memórias de vida e criaçáo. Porto Alegre: EDIPUCRS, 1999, p. 215-219.

BORDINI, Maria da Glória. Erico Verissimo e a literatura portuguesa: da leitura neo-realista à desleitura pós-moderna. In: DUARTE, Leila Parreira (Org.). Para sempre em mim: homenagem à Professora Ângela Vaz Leão. Belo Horizonte: CESPUC/Ed. PUCMINAS, 1999, p. 352-360.

BORDINI, Maria da Glória. A literatura infantil dos anos 80. In: SERRA, Elizabeth D'Angelo (Org.). 30 anos de literatura para crianças e jovens. Campinas: Mercado das Letras; Associação de Leitura do Brasil, 1998, p. $33-45$.

BORDINI, Maria da Glória. Política, Criança e Poesia Infantil. In: PAULINO, Graça (Org.). O jogo do livro infantil. 1. ed. Belo Horizonte: Dimensão, 1997, v. U, p. 45-58.

BORDINI, Maria da Glória. Imaginação Moderna e Intimidade com o leitor. In: SCHMIDT, Simone Pereira; BARBOSA, Márcia Helena Saldanha (Org.). Mario Quintana. 1. ed. Porto Alegre: Unidade Editorial (Cadernos Porto \& Virgula), 1997, v. 14, p. 7-14.

BORDINI, Maria da Glória. Gringa, eu. In: MAESTRI, Mario (Org.). Nós, os ítalo-gaúchos. Porto Alegre, RS: EDUFRGS, 1996.

BORDINI, Maria da Glória. Um contador da História da Literatura. In: VERISSIMO, Erico (Org.). Breve história da literatura brasileira. 3. ed. Sáo Paulo: Globo, 1995, p. 155-167.

BORDINI, Maria da Glória. O Romance Inconformado de Erico Verissimo. In: ZILLES, Urbano (Org.). Gratidáo de ser: homenagem ao Irmáo Elvo Clemente. 1. ed. Porto Alegre: EDIPUCRS, 1994, v. U, p. 85-89.

BORDINI, Maria da Glória. Poesia e consciência lingüística na infância. In: SILVA, Ezequiel Theodoro da (Org.). Leitura e desenvolvimento da linguagem. Porto Alegre: Mercado Aberto, 1989, p. 53-69.

BORDINI, Maria da Glória. Terra e poder. In: VERISSIMO, Erico (Org.). Música ao longe. São Paulo: Círculo do Livro, 1988, p. 235-241. 
BORDINI, Maria da Glória. O temor do além e a subversão do real. In: ZILBERMAN, Regina (Org.). Os preferidos do público. Petrópolis: Vozes, 1987, p. 11-22.

BORDINI, Maria da Glória. Porto Alegre na literatura de Erico. In: FLORES, Hilda Agnes Hübner (Org.). Porto Alegre: História e Cultura. Porto Alegre: Martins Livreiro, 1987, p. 86-90.

BORDINI, Maria da Glória. Crítica e Literatura Infantil nos anos 70 e 80. In: KHÉDE, Sônia Salomão (Org.). Literatura infanto-Juvenil: um gênero polêmico. Porto Alegre: Mercado Aberto, 1986, p. 95-110.

BORDINI, Maria da Glória ; CRUSIUS, A. . Pequeno Dicionário de Autores da Literatura Brasileira. In: FERNANDES, Francisco (Org.). Dicionário Brasileiro Globo. Porto Alegre: Globo, 1978, p. 107-128.

\section{Artigos completos publicados em periódicos}

BORDINI, Maria da Glória. Amor, a insaciável sede: a poesia amorosa de Nuno Júdice. Revista Portuguesa de Humanidades, v. 17, p. 7-20, 2013.

BORDINI, Maria da Glória. Ilhas e continentes: uma poesia de limiares. Mulemba, v. 1, p. 121-131, 2012.

BORDINI, Maria da Glória. Uma professora exemplar. Letras, UFSM, v. 22, p. 09-14, 2012.

BORDINI, Maria da Glória. Poeta apesar de si mesmo. Ipotesi, Juiz de Fora, v. 15, p. 211-224, 2011.

BORDINI, Maria da Glória. Moacyr Scliar e o conto insólito. Webmosaica, v. 3, p. 71-76, 2011.

BORDINI, Maria da Glória. Walter Benjamin, messianismo e materialismo histórico. Webmosaica, v. 3, p. 51-57, 2011.

BORDINI, Maria da Glória. O Verão de Nossa Desimportância. Philia e Filia, v. 01, p. 82-110, 2010.

BORDINI, Maria da Glória. O Prisioneiro: a cidade ocupada. Brasil, Porto Alegre, v. 23, p. 57-80, 2010. 
BORDINI, Maria da Glória. O tradutor poeta. Cadernos de Literatura Brasileira, v. 25, p. 129-137, 2009.

BORDINI, Maria da Glória. Os acervos de escritores sulinos e a memória literária brasileira. Patrimônio e Memória, UNESP, v. 4, p. 1-20, 2009.

BORDINI, Maria da Glória. Podres no coreto. Revista de História, Rio de Janeiro, v. 5, p. 72-75, 2009.

BORDINI, Maria da Glória. Para a Poesia Infantil Ser Poesia. Tigre Albino, v. 1, p. $1-8,2008$.

BORDINI, Maria da Glória. Memórias da Formação do Escritor no Acervo Literário de Erico Verissimo. História da Educação, UFPel, v. 12, p. 95108, 2008.

BORDINI, Maria da Glória. O papel da universidade na promoção da leitura. Vidya, Santa Maria, v. 26, p. 17-24, 2008.

BORDINI, Maria da Glória. Amigos, amigos, literatura à parte: Vianna Moog e Erico Verissimo. Teresa, USP, v. 8/9, p. 205-222, 2008.

BORDINI, Maria da Glória. Herbert Caro nas Cartas de Erico Verissimo. Contingentia, UFRGS, v. 2, p. 15-22, 2007.

BORDINI, Maria da Glória. Política e experimentalismo em Ana Hatherly. Via Atlântica, USP, v. 11, p. 33-45, 2007.

BORDINI, Maria da Glória. Ironia e crítica na poesia de Quintana. Revista do Centro de Estudos Portugueses, UFMG, v. 26, p. 57-71, 2006.

BORDINI, Maria da Glória. A lírica amorosa em Mario Quintana. Nonada, Porto Alegre, v. 9, p. 51-61, 2006.

BORDINI, Maria da Glória. Enfim, um poeta transnacional. Arquipélago, Porto Alegre, v. 5, p. 63-64, 2006.

BORDINI, Maria da Glória. O Acervo de Quintana: poesia em estado natural. Arquipélago, Porto Alegre, v. 4, p. 49-50, 2006.

BORDINI, Maria da Glória. Estudos culturais e estudos literários/A personagem na perspectiva dos Estudos Culturais. Letras de Hoje, v. 41, p. 11/135-22/142, 2006.

BORDINI, Maria da Glória. Ética e criação literária para crianças. 
Desenredo, PPGL/UPF, Passo Fundo, RS, v. 1, n.1, p. 64-75, 2005.

BORDINI, Maria da Glória. Erico Verissimo: Um Intelectual Independente. Ciências e Letras, Porto Alegre, Porto Alegre, RS, v. 38, p. 8-13, 2005.

BORDINI, Maria da Glória. Um Escritor de Integridade a Toda Prova (Apresentação). Nonada, Porto Alegre, Porto Alegre, RS, v. 8, p. 11-12, 2005.

BORDINI, Maria da Glória. Uma história dos efeitos. Letras de Hoje, Porto Alegre, RS, v. 40, n.4, p. 7-13, 2005.

BORDINI, Maria da Glória. Acervos de escritores e o descentramento da história da literatura. O Eixo e a Roda, Belo Horizonte, v. 11, p. 15-24, 2005.

BORDINI, Maria da Glória. A atualidade da obra de Erico Verissimo. Revista Signo, Santa Cruz do Sul, RS, v. 30, n.49, p. 35-46, 2005.

BORDINI, Maria da Glória. Poesia e ensino universitário. Vidya, Santa Maria, RS, v. 21, n. 37, p. 43-54, 2004.

BORDINI, Maria da Glória. Os mortos de Joyce a Huston. Letras de Hoje, Porto Alegre, v. 39, n.2, p. 97-111, 2004.

BORDINI, Maria da Glória. Do moderno ao pós-moderno. Cadernos de Literatura Brasileira, São Paulo, SP, v. 16, p. 141-157, 2003.

BORDINI, Maria da Glória. Acervos e criação literária em O Senhor Embaixador, de Erico Verissimo. Cadernos do Centro de Pesquisas Literárias, PUC/RS, Porto Alegre, RS, v. 8, n.1, p. 143-148, 2002.

BORDINI, Maria da Glória. Acervos literários brasileiros em rede digital. Leituras Revista da Biblioteca Nacional, Lisboa, v. 3, n.5, p. 127-132, 2000.

BORDINI, Maria da Glória. O Continente de Sáo Pedro: Éden violado. Letterature d'America, Roma, v. 12-13, n.73-74, p. 41-55, 2000.

BORDINI, Maria da Glória. Erico Verissimo e a literatura brasileira nos Estados Unidos. Brasil, Porto Alegre, Porto Alegre/Providence, v. 13, n.23, p. $45-54,2000$.

BORDINI, Maria da Glória. História e Poesia No Romanceiro da 
Inconfidência. Brasil, Porto Alegre, Providence, EUA; Porto Alegre, v. 9, n.15, p. 81-96, 1996.

BORDINI, Maria da Glória. Tempo e Narrativa. Veritas, Porto Alegre, v. 41, n.162, p. 339-347, 1996.

BORDINI, Maria da Glória. Os Acervos do Centro de Pesquisas Literárias da PUCRS. Manuscrítica: Revista de Crítica Genética, São Paulo, v. --, n.6, p. 83-92, 1996.

BORDINI, Maria da Glória. A representação da história na poesia: o caso Murilo Mendes. Letras de Hoje, v. 31, p. 119-128, 1996.

BORDINI, Maria da Glória. A Formação do Profissional de Letras. Adverso, Porto Alegre, v. 5, n.7, p. 46-50, 1995.

BORDINI, Maria da Glória. O Mal da Cidade. Cadernos do Centro de Pesquisas Literárias, PUC/RS, Porto Alegre, v. 1, n.4, p. 31-40, 1995.

BORDINI, Maria da Glória. A Hora do Sétimo Anjo: Criação Em Processo. Nova Renascença, Lisboa, v. -, n.57, p. 429-440, 1995.

BORDINI, Maria da Glória. Mensagem: Lírica e História. Discursos: estudos de língua e cultura portuguesa, Lisboa, v. -, n.7, p. 45-62, 1994.

BORDINI, Maria da Glória. O Questionamento Politico Em O Arquipélago, de Erico Verissimo. Letras de Hoje, Porto Alegre, v. 27, n.1, p. 99-110, 1992.

BORDINI, Maria da Glória. Doutor Fausto e O Esgotamento do Espontaneo. Organon, UFRGS, Porto Alegre, v. 6, n.19, p. 53-60, 1992.

BORDINI, Maria da Glória. Narratividade, Modo Literário e Gênero Narrativo em $O$ Mandarim, de Eça de Queiros. Letras de Hoje, Porto Alegre, v. 26, n.1, p. 21-48, 1991. 